Check for updates

Cite this: RSC Adv., 2017, 7, 27946

Received 20th March 2017 Accepted 20th May 2017

DOI: $10.1039 / c 7 r a 03278 a$

rsc.li/rsc-advances

\section{Microwave-assisted rapid synthesis of a polyether from a plant oil derived monomer and its optimization by Box-Behnken design}

\begin{abstract}
Reza Ahmadi (iD and Aman Ullah (iD *
In this study, a new strategy for making polyethers from $\alpha$-olefin (1-decene) was developed using microwave irradiation and compared with a conventional method. The olefin was epoxidized and subjected to catalytic polymerization using both conventional and microwave synthesis techniques. The conventional epoxidation reaction of 1-decene took 1 hour while microwave-assisted epoxidation was completed in $\sim 5$ minutes. A three-factor, three-level Box-Behnken response surface design was employed to investigate the effect of the process parameters such as time, temperature, and the solvent-monomer ratios on the yield of the ring-opening polymerization of 1,2-epoxydecane using MMAO-12/2,4-pentanedione. The obtained experimental data were fitted to a transferred second-order polynomial equation using multiple regression analysis with a high coefficient of determination $\left(R^{2}\right)$ value of 0.9881 . Interestingly, the optimal predicted parameters based on all independent variables (reaction time $9.97 \mathrm{~min}$, the temperature $99.69{ }^{\circ} \mathrm{C}$, and solvent to monomer ratio $5.27: 5$ ) were determined by a maximum polyether yield of $82.51 \%$, which was further confirmed by validation experiments. The synthesized polymers were characterized by using proton nuclear magnetic resonance spectroscopy $\left({ }^{1} \mathrm{H}-\mathrm{NMR}\right)$, attenuated total reflectance Fourier transform infrared spectroscopy (ATR-FTIR), differential scanning calorimetry (DSC), thermal gravimetric analysis (TGA) and size exclusion chromatography (SEC). A high molecular weight polyether was synthesized with a melting temperature as high as $88.64{ }^{\circ} \mathrm{C}$ and a decomposition in the range of $325-418{ }^{\circ} \mathrm{C}$. The rapid synthesis of a biopolyether with high molecular mass is extremely attractive both from an academic and industrial point of views.
\end{abstract}

\section{Introduction}

The finite availability of petroleum resources and the destructive effect of the fossil-based products on the environment have attracted the attention of scientists, governmental and private agencies to use sustainable and environmentally friendly materials. ${ }^{1,2}$ The synthesis of biopolymers from renewable resources, therefore, has been considered as a promising strategy for releasing the polymer industry from its dependence on petroleum resources. ${ }^{3}$ An eco-friendly and sustainable alternative for plastic materials production is the utilization of monomers from plant-derived resources (proteins, carbohydrates, lipids) as promising starting materials to replace some or all of the synthetic chemicals and polymers in many applications. ${ }^{4}$ However, biopolymers from proteins and carbohydrates are not a good choice to replace petroleum-based plastics because these are moisture sensitive, difficult to process and brittle when used without the addition of a plasticizer. In this context vegetable oils, being hydrophobic, have attracted more

Department of Agricultural, Food, and Nutritional Science, University of Alberta, 4-10 Agriculture/Forestry Centre, Edmonton, Alberta, Canada T6G 2P5. E-mail: ullah2@ ualberta.ca attention compared to other bio-based compounds (i.e., polysaccharides, or proteins) for the production of biopolymers. Economic advantages and worldwide availability make vegetable oils interesting options for the industry. While diverse chemistry can be applied to vegetable oils for the production of several types of monomers and polymers, only minor modification reactions are necessary in order to obtain suitable monomers for many different applications. ${ }^{5}$

Canola oil, ${ }^{6}$ soybean oil, ${ }^{7}$ castor oil, ${ }^{8}$ and high oleic sunflower oil $^{5}$ are the common vegetable oils used directly for making biopolymers. Another approach, however, is to design biodegradable polymers through synthesis of monomers from plant oils and further polymerization into desired biopolymers. ${ }^{9-12}$ Among several other methods, olefin metathesis has recently emerged for the synthesis of monomers from plant oils. ${ }^{13}$ The olefin metathesis is a potentially useful synthetic transformation tool for the chemical conversion and formation of new carbon-carbon double bonds. ${ }^{14}$ It is generally categorized into ring-opening, ring closing, and cross-metathesis groups. Olefin cross-metathesis is a catalytic reaction between two alkene molecules that results in redistribution of alkylidene groups. The cross-metathesis of an olefinic compound could be done with ethylene or other olefins called ethenolysis and 
alkenolysis, respectively. ${ }^{15}$ Recently, our group has successfully reported remarkably efficient microwave-assisted ethenolysis and alkenolysis (using 1,5-hexadiene) of lipids into various monomers using $2^{\text {nd }}$ generation Grubbs and Hoveyda-Grubbs catalysts. ${ }^{16}$ Interestingly, the solvent free rapid conversion of the substrates resulted in high value linear $\alpha$-olefin monomers like methyl 9-decenoate, and 1-decene within few minutes. The resulting monomers can be manipulated to produce different kinds of polymers like polyethers which find applications in different industries such as pharmaceutical, cosmetic, adhesive, paint, textile fiber, and ceramic. ${ }^{17,18}$ Conventional methods have been used as the main applicable process for the synthesis of the polyethers. However, the production of polyether from vegetable oils and the manipulated monomers through conventional methods have some limitations including long reaction time, low yield, the occurrence of side reactions, and the use of a high amount of solvent. In addition, slow catalystmonomer interaction and heating flow through conduction leading to heterogeneous reaction environment and limitations to control activation parameters in the conventional heating methods are some of the shortcomings of the conventional methods. ${ }^{11,19-22}$

The use of microwave (MW) irradiation is emerging as an alternative heating technique for product development and has provided new application opportunities to overcome abovementioned limitations of conventional heating methods., ${ }^{3,20,21,23}$ Ring-opening polymerization (ROP) of cyclic monomers such as 2-ethyl-2-oxazolines, ${ }^{24} \varepsilon$-caprolactone, ${ }^{21} \mathrm{D}, \mathrm{L}^{-}$ lactide, ${ }^{22}$ and $p$-dioxanone ${ }^{25}$ in the presence of different metal catalysts and macro-initiators have also been studied under MW conditions.

The present study describes the production of a high molecular weight polyether from 1,2-epoxydecane synthesized from 1-decene using both the conventional and the MW methods. To the best of our knowledge, this is the first study reporting optimized epoxidation of 1-decane using an oxygen donor, without using catalyst, at a relatively short time with a high yield using conventional method. The epoxidation of 1decene was also studied using the MW. The synthesized epoxy was polymerized using microwave-assisted catalytic ROP to polyether with really high molecular weight in the present and absence (bulk polymerization) of solvent in just a few minutes.

\section{Experimental}

\subsection{Materials}

1-Decene (94\%), 3-chloroperoxybenzoic acid ( $m$-CPBA $\leq 77 \%$ ), modified methyl aluminoxane (MMAO-12, 7 wt\% aluminum in toluene), anhydrous sodium sulfate $(\geq 99 \%)$, dichloromethane (DCM, $\geq 99.5 \%$ ), ethyl acetate (anhydrous, 99.8\%), hexane, silica gel for chromatography (Whatman, $60{ }^{\circ} \mathrm{A}, 70-230 \mathrm{mesh}$ ), methanol (anhydrous, 99.8\%), and tetrahydrofuran (THF, $\geq 99 \%$ ) were purchased from Sigma-Aldrich. 2,4-Pentanedione (ReagentPlus ${ }^{\circledR}, \geq 99 \%$ ) and toluene (anhydrous, 99.8\%) were dried over anhydrous sodium sulfate overnight before use.

\subsection{Instrumentation}

A Bruker Alpha FTIR spectrophotometer (Bruker Optics, Esslingen, Germany) equipped with a single bounce diamond ATR crystal was employed to collect spectrum at a resolution of $4 \mathrm{~cm}^{-1}$ over the range of $410-4000 \mathrm{~cm}^{-1}$. All sample spectra were recorded at 16 scans and averaged using OPUS software (Bruker version 6.5). A background spectrum of the clean ATR crystal was also collected before applying and collecting the sample spectrum. Finally, the analysis of the spectrum was done using Nicolet Omnic software (version 8).

Proton nucleic magnetic resonance $\left({ }^{1} \mathrm{H}\right.$ NMR) spectra were collected in deuterated chloroform $\left(\mathrm{CDCl}_{3}\right)$ using a Varian Inova spectrometer (Varian, CA) at $400 \mathrm{MHz}$ and $26.9^{\circ} \mathrm{C}$. The analysis of the spectrum was done using the MestReNova software (version 11.0).

X-ray Photoelectron Spectroscopy (XPS) was used to study the chemical composition of the polyether. The XPS measurements were conducted on ULTRA spectrometer (Kratos Analytical). The base pressure in the analytical chamber was lower than $3 \times$ $10^{-8} \mathrm{~Pa}$. The spectrometer was equipped with a monochromatic Al $\mathrm{K} \alpha$ source $(h \nu=1486.6 \mathrm{eV})$ source operated at a power of $140 \mathrm{~W}$. The spot size used was $400 \times 700 \mu \mathrm{m}$. The resolution of the instrument is $0.55 \mathrm{eV}$ for $\mathrm{Ag} 3 \mathrm{~d}$ and $0.70 \mathrm{eV}$ for $\mathrm{Au} 4 \mathrm{f}$ peaks. The survey scans were taken in the range of $0-1100 \mathrm{eV}$ with analyzer pass energy of $160 \mathrm{eV}$ and a step of $0.4 \mathrm{eV}$. For the highresolution spectra, the pass-energy was $20 \mathrm{eV}$ with a step of $0.1 \mathrm{eV}$. The sample charging if any was compensated by an electron flood gun. The data were processed using the vision-2 instrument software. The binding energy of each photopeak was referenced to the $\mathrm{C} 1 \mathrm{~s}$ level at $284.8 \mathrm{eV}$. Compositions were calculated from the high-resolution spectra using linear background and sensitivity factors provided by the instrument database.

The molecular weight and polydispersity of the polyethers were determined using gel permeation chromatography (GPC). The GPC system was equipped with Styragel HR5E GPC column $\left(300 \times 7.8 \mathrm{~mm}^{2}\right.$ i.d., particle size $=5 \mu \mathrm{m}$, Waters Corporation $)$. An isocratic Agilent 1100 pump (Agilent Technologies; CA) equipped with an evaporative light scattering detector (Alltech ELSD 2000, Mandel Scientific Company, Canada) was used. The THF was used as the eluent at a flow rate of $1 \mathrm{~mL} \mathrm{~min}^{-1}$, sample concentrations $0.5 \mathrm{mg} \mathrm{mL}^{-1}$, and injection volumes were $10 \mu \mathrm{L}$. The Agilent Polystyrene EasiVial PS-H standard kit with known molecular weight in the range of $162-7 \times 10^{6} \mathrm{~g} \mathrm{~mol}^{-1}$ and the polydispersity $\leq 1$ was used to generate the calibration curve by the Agilent GPC-Addon Rev. B. 01.01 Software.

The differential scanning calorimetric (DSC) analysis of all samples was carried out by a Perkin-Elmer (Pyris 1, Norwalk, CT, USA) calorimetric apparatus equipped with a cooling system in a range of $-60-120{ }^{\circ} \mathrm{C}$ at a rate of $5{ }^{\circ} \mathrm{C} \min ^{-1}$ under a dry nitrogen gas atmosphere. The heat flow and temperature calibration of the instrument were established by a sample of pure indium. All the DSC measurements were performed following the ASTM E1356-08 (Reapproved 2014) standard procedure. ${ }^{26}$ Thermogravimetric analysis (TGA) was performed on a PerkinElmer (Pyris 1, Waltham, MA, USA). Approximately $13 \mathrm{mg}$ of 
the specimen was loaded in the open platinum pan and scanned from 10 to $550{ }^{\circ} \mathrm{C}$, at a heating rate of $10^{\circ} \mathrm{C} \mathrm{min}^{-1}$ under a nitrogen atmosphere with $100 \mathrm{~mL} \min ^{-1}$ purging flow following the ASTM D3850-12 (2012) standard. ${ }^{27}$

\subsection{Synthesis of 1,2-epoxydecane from 1-decene (Scheme}

1a)

The synthesis of 1,2-epoxydecane from 1-decene using conventional heating was carried out using reported method with some modifications. ${ }^{2}$ Briefly, dichloromethane $(10 \mathrm{~mL})$ and 1-decene $(7 \mathrm{mmol})$ were added into a round-bottom flask equipped with a magnetic stir bar and placed into an ice bath. The initial exothermic epoxidation reaction of 1-decene was then controlled by gradual addition and dissolution of $m$-CPBA ( 8.9 $\mathrm{mmol}$ ) into the reaction mixture at $0{ }^{\circ} \mathrm{C}$. After that, the mixture was stirred at $900 \mathrm{rpm}$ for different time points $(15,30,60$, and $180 \mathrm{~min}$ ) at room temperature to determine the best yield of 1,2epoxydecane. The epoxy monomer was separated by silica gel column chromatography ( $5 \%$ of the ethyl acetate in hexane). The solvents were evaporated by rotary evaporator and resulting 1,2-epoxydecane was dried over sodium sulfate. Finally, dried 1,2-epoxydecane was purged with a nitrogen line in a glass vial equipped with a septum cap. The vial was sealed with parafilm and stored at $4{ }^{\circ} \mathrm{C}$ for further polymerization. The yield of the epoxidation reaction was calculated by the following equation:

$$
\text { Yield } \%=(\text { actual yield } / \text { theoretical yield }) \times 100
$$

Where the actual yield is equal to the weight of the product after the reaction and theoretical yield is equal to $1.11 \mathrm{~g}$ of $1,2-$ epoxydecane per $1 \mathrm{~g}$ of 1-decene. The structure and purity of obtained 1,2-epoxydecane were confirmed using ${ }^{1} \mathrm{H}$ NMR (Fig. 4) and ATR-FTIR spectroscopy (Fig. 5).

\subsection{Synthesis of 1,2-epoxydecane from 1-decene using MW (Scheme 1b)}

An MW system CEM-Discover (120 V, Matthews, USA) was used as a source of microwave irradiation for performing the epoxidation reaction of 1-decene. Dichloromethane $(6.5 \mathrm{~mL})$ was mixed with 1-decene $(3.5 \mathrm{mmol})$ in an MW reaction vessel containing a magnetic stir bar and placed into an ice bath. The $m$-CPBA $(4.5 \mathrm{mmol})$ was gradually added to the mixture at $0{ }^{\circ} \mathrm{C}$. The vessel was then placed in the MW reactor with the adjusted pressure and power $(250 \mathrm{psi}, 250 \mathrm{~W})$ and reaction conducted for 5 and 6 min at $25{ }^{\circ} \mathrm{C}$. Column chromatography, rotary evaporator and drying on the sodium sulfate steps were done same as in the conventional method to purify the resulted 1,2epoxydecane.

\subsection{Ring-opening polymerization of 1,2-epoxydecane} (conventional method)

The conventional ring-opening polymerization of 1,2-epoxydecene was carried out using reported method with some modifications. ${ }^{11}$ Briefly, the polymerization reaction was planned in three different steps: "in situ" catalyst preparation, polymerization, and polyether precipitation. For "in situ" catalyst preparation a $50 \mathrm{~mL}$ dried round bottom flask containing a magnetic stir bar was charged with dried toluene (17 $\mathrm{mL}$ ) and sealed with a rubber cap and parafilm. The oxygen in toluene and the flask was eliminated using a nitrogen line (purging toluene for $15 \mathrm{~min}$ and the headspace for $15 \mathrm{~min}$ ) and then the flask was quickly sealed with parafilm again. MMAO-12 solution $(215 \mu \mathrm{L})$ and 2,4-pentanedione $(50 \mu \mathrm{L})$ were added stepwise into the purged flask with a purged microliter glass syringe (Hamilton Co., USA). Because of the extreme sensitivity of the catalyst to moisture and oxygen using dried reaction flasks and sealing them properly after adding each chemical is critical in these steps. The mixture was stirred for $5 \mathrm{~min}$ at room temperature to prepare the catalyst. For the polymerization step, the dried and purged 1,2-epoxydecane $(10 \mathrm{mmol})$ was added to the catalyst mixture with a purged microliter glass syringe and the flask was quickly sealed with parafilm again. The mixture was heated in the silicon oil bath at $100{ }^{\circ} \mathrm{C}$ for 24 hours. The catalyst was quenched with $0.5 \mathrm{~mL}$ methanol to stop the reaction. Polyether precipitation was performed at the last step. The quenched highly viscous mixture from the previous step was diluted with $35 \mathrm{~mL}$ of toluene, poured into $300 \mathrm{~mL}$ methanol/concentrated aqueous $\mathrm{HCl}(90 / 10)$ and stirred rapidly for $15 \mathrm{~min}$. Afterward, the supernatant was decanted and the produced white to pale yellow polyether was washed twice with methanol. Finally, the resulted polyether was dried in an oven at $40{ }^{\circ} \mathrm{C}$ overnight.

\subsection{Ring-opening polymerization of 1,2-epoxydecane (MW method)}

The same three steps used in the conventional method were applied in the MW reaction. The yield of the reaction was optimized using three temperatures $\left(50,75,100^{\circ} \mathrm{C}\right)$, microwave irradiation time $(4,7,10 \mathrm{~min})$ and the solvent-monomer ratio or toluene-1,2-epoxydecane ratio $\left(0: 5,3: 5,6: 5 \mathrm{~mL} \mathrm{mmol}^{-1}\right)$. For the reactions containing the solvent, the following procedure was carried out. Two dried MW tubes equipped with magnetic bars were charged with 3 and $6 \mathrm{~mL}$ of dried toluene and sealed with a septum cap and parafilm. The oxygen in toluene and the tube was eliminated. MMAO-12 solution (107 $\mu \mathrm{L})$ and 2,4-pentanedione $(25 \mu \mathrm{L})$ were added stepwise into the tube as mentioned in the conventional method. The mixture was stirred for $5 \mathrm{~min}$ to prepare the catalyst. 1,2-Epoxydecane (5 $\mathrm{mmol}$ ) was then added to the catalyst mixture with the purged microliter glass syringe. The sealed tube was put in the MW and run with the adjusted pressure and power $(250 \mathrm{psi}, 250 \mathrm{~W})$, different temperatures $\left(50,75,100{ }^{\circ} \mathrm{C}\right)$ and different time intervals $(4,7,10 \mathrm{~min})$. Finally, the reaction was quenched with $0.25 \mathrm{~mL}$ methanol and diluted with $18 \mathrm{~mL}$ of toluene. The polyether was precipitated with $150 \mathrm{~mL}$ methanol/concentrated aqueous $\mathrm{HCl}(90 / 10)$ after 15 min stirring, washed and dried as mentioned in the conventional method.

\subsection{Bulk ring-opening polymerization of 1,2-epoxydecene (MW method)}

For bulk ROP, the catalyst was prepared without solvent in the first step. A dried MW tube equipped with a magnetic stir bar 
was charged with 2,4-pentanedione $(200 \mu \mathrm{L})$, capped and sealed with parafilm tightly. The oxygen in 2,4-pentanedione and the tube was eliminated using a nitrogen line (purging 2,4-pentanedione for $5 \mathrm{~min}$ and the headspace for $15 \mathrm{~min}$ ) and then the tube was quickly sealed with parafilm again. The purged tube was charged with the MMAO-12 solution $(430 \mu \mathrm{L})$ and sealed as mentioned before. The mixture was stirred for $5 \mathrm{~min}$ to prepare the catalyst. After that, 1,2-epoxydecane $(20 \mathrm{mmol})$ was added to the catalyst mixture with the purged microliter glass syringe. The rest of the process including the reaction in the MW, precipitation, washing and drying of the resulting polyether was followed as mentioned in the previous section.

\subsection{Experimental design for optimization of the polymerization using MW}

The response surface methodology (RSM) was employed to determine the optimum conditions for ring-opening polymerization of 1,2-epoxydecane using the MW heating. RSM as an efficient multivariate technique provides a faster and more economical method allowing more than one variable to be optimized simultaneously. The experimental design and statistical analysis were performed using the Design Expert software (6.0.2, Stat-Ease Inc., USA). The experiments were performed based on the Box-Behnken Design (BBD). BBD has been frequently used as a suited design for fitting a quadratic surface and suitable chemometric tools for the process optimization. BBD reduce the number of experiments resulting in low solvent consumption and considerably less laboratory work. Moreover, BBD has a uniform precision by adequate selection of the number of center points. ${ }^{28,29}$ In the present study, the effects of the three independent variables at three levels (reaction times of $4,7,10 \mathrm{~min}\left(X_{1}\right)$, temperatures of $50,75,100{ }^{\circ} \mathrm{C}\left(X_{2}\right)$ and solvent-monomer ratio of $\left.0: 5,3: 5,6: 5 \mathrm{~mL} \mathrm{mmol}^{-1}\left(X_{3}\right)\right)$ on the response or polymerization yield percent of the reaction (PY) was investigated.

The low, center and high factor levels were coded as -1 , 0 and +1 . The code with positive sign represents a synergistic effect of the variables while the negative one indicates an antagonistic effect of the variables. The variables coding was performed by the following equation: ${ }^{28}$

$$
x_{i}=\frac{X_{i}-X_{z}}{\Delta X_{i}} \quad i=1,2,3, k
$$

where $x_{i}=$ the dimensionless value of a process variable; $X_{i}=$ the real value of an independent variable; $X_{z}=$ the real value of an independent variable at the center point; and $\Delta X_{i}=$ the step change of the real value of the variable $i$ corresponding to a variation of a unit for the dimensionless value of the variable $i$.

17 experiments were designed with five center points to allow calculations of the response function at intermediate levels and estimation of the system performance at any experimental point within the studied range. The calculation of the total number of experiments $(N)$ was done by the following equation: ${ }^{28}$

$$
N=K+k^{2}+C_{\mathrm{p}}
$$

Table 1 Box-Behnken design matrix of real and coded values along

\begin{tabular}{|c|c|c|c|c|c|}
\hline & \multicolumn{3}{|c|}{ Real (coded) values ${ }^{a}$} & \multicolumn{2}{|c|}{ Polymerization yield (\%) } \\
\hline & $X_{1}$ & $X_{2}$ & $X_{3}$ & Experimental $^{b}$ & Predicted \\
\hline 1 & $10(+1)$ & $50(-1)$ & $3: 5(0)$ & 2.50 & 1.18 \\
\hline 2 & $7(0)$ & $75(0)$ & $3: 5(0)$ & 12.30 & 13.43 \\
\hline 3 & $7(0)$ & $75(0)$ & $3: 5(0)$ & 10.69 & 13.43 \\
\hline 4 & $4(-1)$ & $50(-1)$ & $3: 5(0)$ & 0.30 & -0.08 \\
\hline 5 & $7(0)$ & $100(+1)$ & $6: 5(+1)$ & 72.56 & 66.62 \\
\hline 6 & $7(0)$ & $75(0)$ & $3: 5(0)$ & 14.05 & 13.43 \\
\hline 7 & $4(-1)$ & $100(+1)$ & $3: 5(0)$ & 21.67 & 25.74 \\
\hline 8 & $10(+1)$ & $75(0)$ & $0: 5(-1)$ & 3.50 & 3.75 \\
\hline 9 & $7(0)$ & $100(+1)$ & $0: 5(-1)$ & 40.86 & 37.66 \\
\hline 10 & $7(0)$ & $50(-1)$ & $0: 5(-1)$ & 0.00 & 0.75 \\
\hline 11 & $7(0)$ & $75(0)$ & $3: 5(0)$ & 15.35 & 13.43 \\
\hline 12 & $4(-1)$ & $75(0)$ & $0(-1)$ & 0.00 & -0.25 \\
\hline 13 & $10(+1)$ & $75(0)$ & $6(+1)$ & 13.64 & 14.82 \\
\hline 14 & $7(0)$ & $50(-1)$ & $6(+1)$ & 1.11 & 1.84 \\
\hline 15 & $10(+1)$ & $100(+1)$ & $3(0)$ & 70.40 & 73.69 \\
\hline 16 & $7(0)$ & $75(0)$ & $3(0)$ & 14.98 & 13.43 \\
\hline 17 & $4(-1)$ & $75(0)$ & $6(+1)$ & 1.10 & 0.49 \\
\hline
\end{tabular}
with experimental and predicted values of the polymerization yield (\%)

${ }^{a} X_{1}$ : time (min); $X_{2}$ : temperature $\left({ }^{\circ} \mathrm{C}\right) ; X_{3}$ : solvent-monomer ratio. ${ }^{b}$ Average of three experiments.

where $C_{\mathrm{p}}$ is the replicate number of the center point and $k$ is the factor number.

The actual design of experiments is shown in Table 1.

The mathematical relationship of the response to the three significant independent variables $\left(X_{1}, X_{2}\right.$, and $\left.X_{3}\right)$ can be approximated by the quadratic polynomial equation, shown as follow:

$\mathrm{PY}=\beta_{0}+\beta_{1} X_{1}+\beta_{2} X_{2}+\beta_{3} X_{3}+\beta_{12} X_{1} X_{2}+\beta_{13} X_{1} X_{3}+\beta_{23} X_{2} X_{3}+$ $\beta_{11} X_{1}^{2}+\beta_{22} X_{2}^{2}+\beta_{33} X_{3}^{2}$

where PY $=$ predicted yield percent, $\beta_{0}=$ the constant, $\beta_{1}, \beta_{2}$, and $\beta_{3}=$ linear coefficients, $\beta_{12}, \beta_{13}$, and $\beta_{23}=$ cross product coefficients, and $\beta_{11}, \beta_{22}$, and $\beta_{33}=$ quadratic coefficients.

For reaching to the optimum values of the factors, the regression equation was solved; the surface of the counter response surface plot was analyzed, and also the constraints for the levels of the variables were set up.

\section{Results and discussion}

\subsection{Synthesis of 1,2-epoxydecane from 1-decene}

This study initially investigated the conventional and the MW methods for epoxidation of 1-decene. The epoxidation reaction was performed in the presence of $m$-CPBA as the oxidant in both methods. The percent yield of the 1,2-epoxydecane at four different time intervals using conventional heating is presented in Fig. 1. Higher reaction time favored the epoxidation reaction. When the reaction time increased from 15 to $60 \mathrm{~min}$, the percent yield increased significantly $(p<0.05)$ from $77.56 \%$ to more than $93 \%$. However, increasing the reaction time to more than $60 \mathrm{~min}$ did not further increase the product yield. 


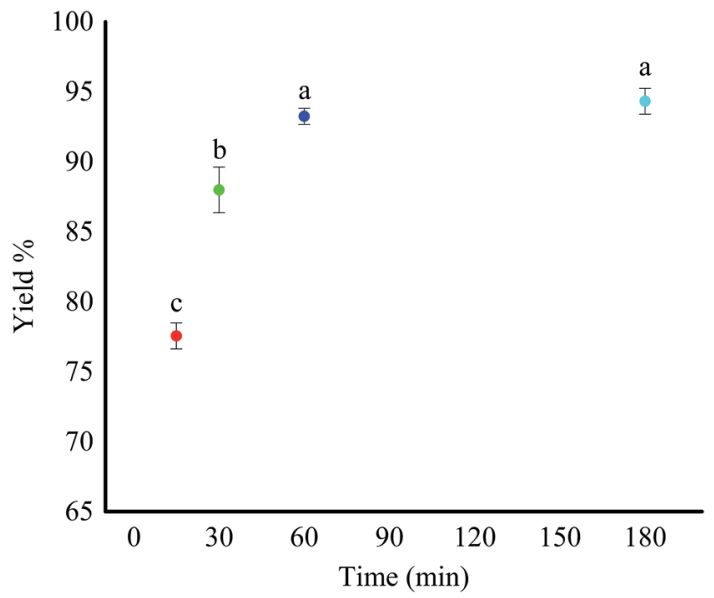

Fig. 1 The yield\% of the produced 1,2-epoxydecane in the conventional method. Note: $a, b$ and $c$ are different letters representing significant differences $(p<0.05)$ between the means obtained by Duncan's test.

Therefore, $60 \mathrm{~min}$ was chosen as the optimum time for the epoxidation of 1-decene using the conventional method. Epoxidation of 1-decane has been reported in the literature using different catalyst systems. Warwel et al. used hydrogen peroxide in ethyl acetate with Novozym $435 \AA$ as a chemo-enzymatic catalyst to oxidize 1-decene. ${ }^{\mathbf{1 1 , 3 0}}$ The reported yield of 1,2-epoxydecane after 16 hours at $40{ }^{\circ} \mathrm{C}$ was only $85 \%$ which is lower than what was obtained in our study. Ho et al. reported another catalytic system for the epoxidation of 1-decene. ${ }^{31}$ They used Mn $\left(\mathrm{ClO}_{4}\right)_{2}$ as the catalyst in acetonitrile/water with different commercial oxidants. Interestingly, when $m$-CPBA was used as the oxidant the reaction yield was only $\sim 47 \%$ which is significantly lower than the yield obtained in our study. Epoxidation of 1-decene using a complex catalytic system of $\mathrm{Na}_{2} \mathrm{WO}_{4}$ dihydrate, (aminomethyl) phosphonic acid, and methyltrin-octyl ammonium hydrogen sulfate with hydrogen peroxide for 4 hours at $90{ }^{\circ} \mathrm{C}$ yielded 99\% 1,2-epoxydecane which is comparable to our results. ${ }^{32}$

An MW system (250 psi pressure, $250 \mathrm{~W}$ power) was employed to study the effect of MW irradiation on the epoxidation of 1-decene in the next step (Scheme 1b). In the course of the study, the best result was achieved when the microwave irradiation was applied just for $5 \mathrm{~min}$ in the presence of $m$-CPBA with a yield of $67.13 \%$. Although the epoxidation reaction was successful, the yield of the reaction was significantly lower than the 15 min heating in the conventional method (Fig. 1). When the reaction time exceeded $5 \mathrm{~min}$, extra peaks appeared in the ${ }^{1} \mathrm{H}$ NMR spectrum of the resulted product. The presence of hydroxyl peak at $3.65 \mathrm{ppm}$ can be an indication of the cleavage of oxirane ring. The interference of water in the reaction mixture is potentially the reason for the observed oxirane ring break down. $m$-CPBA is the source of water in the reaction because it is not stable without water. Therefore, microwave irradiation does not appear to be a suitable method for epoxidation of 1-decene when $m$-CPBA is used as the oxidant.

\subsection{Ring-opening polymerization of 1,2-epoxydecane (conventional method)}

The ring-opening polymerization of 1,2-epoxydecane was carried out using previously reported procedure with some modifications. ${ }^{\mathbf{1 1}}$ Briefly, the polymerization of 1,2-epoxydecane was performed to a quantitative conversion at $100{ }^{\circ} \mathrm{C}$ for 24 hours using the MMAO-12/2,4-pentanedione as the catalyst (Scheme 2). A white to pale yellow polyether was produced by precipitation in methanol/concentrated HCL (90/10) with $74.38 \%$ yield. The obtained polyether was soluble in 1,4-dioxane at room temperature but at $50{ }^{\circ} \mathrm{C}$ in THF. The molecular weight of the polyether was determined by GPC. The molecular weight

a)

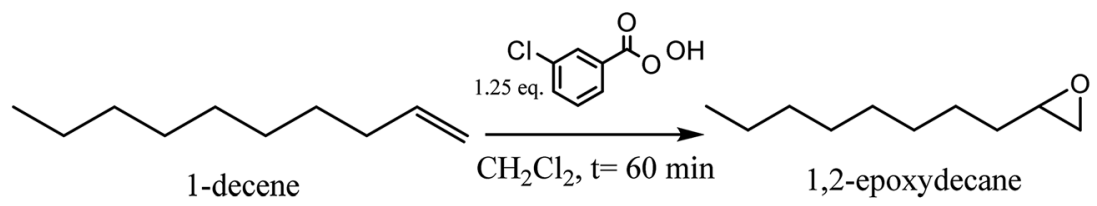

b)

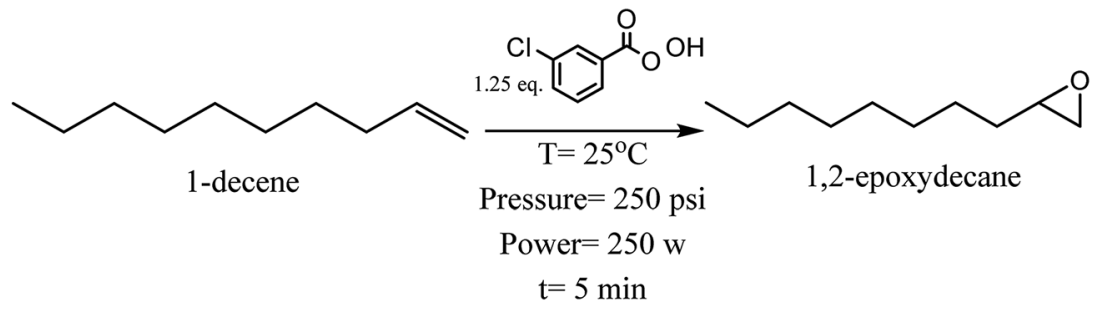

Scheme 1 Synthesis of 1,2-epoxydecane from 1-decene (a) conventional method (b) microwave irradiation method. 


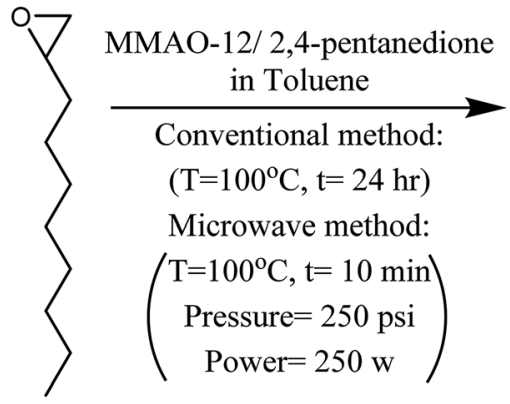

1,2-epoxydecane

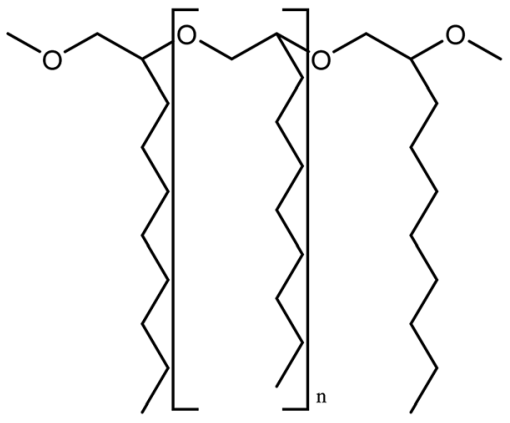

Polyether

Scheme 2 Synthesis of polyether from 1,2-epoxydecane.

of the polyether was more than $2.4 \times 10^{6} \mathrm{~g} \mathrm{~mol}^{-1}$ and polydispersity 1.2 .

\subsection{Ring-opening polymerization of 1,2-epoxydecane (MW method)}

3.3.1. BBD analysis. In accordance with our trial experiments, three independent variables that could potentially affect the yield percent of the polymerization were chosen to be time, temperature and solvent-monomer ratio. In order to study the combined effects of the variables on the PY, experiments were conducted based on the different combinations of the variables using statistically designed experiments.

The observed and predicted PY results are shown in Table 1. The adequacy of the model was checked based on the experimental data to ascertain whether the approximating model would provide poor or misleading results. As shown in Table 2, all of the linear, interactive (two factor interactions $=2 \mathrm{FI}$ ), quadratic and cubic models were fitted to the experimental data. The adequacy of these models was investigated through three different tests namely the sequential model sum of squares, lack of fit tests and model summary statistics. The

Table 2 Sequential model fitting for yield\% of ring-opening polymerization of 1,2-epoxydecane through microwave method ${ }^{a}$

Sequential model sum of squares

\begin{tabular}{lccccc}
\hline Source & Sum of squares & DF & Mean square & $F$-Value & Prob $>F$ \\
\hline Mean & 213.72 & 1 & 213.72 & & \\
Linear & 77.63 & 3 & 25.88 & 19.81 & $<0.0001$ \\
2FI & 3.18 & 3 & 1.06 & 0.77 & 0.5371 \\
Quadratic & 12.67 & 3 & 4.22 & 4.22 & 0.0004 \\
Cubic & 0.85 & 3 & 4.09 & - & 0.1035 \\
Residual & 0.28 & 4 & 0.069 & - & Suggested \\
Total & 308.34 & 17 & 18.14 & - & Aliased \\
\hline
\end{tabular}

Lack of fit tests

\begin{tabular}{|c|c|c|c|c|c|c|}
\hline Linear & 16.70 & 9 & 1.86 & 26.76 & 0.0032 & \\
\hline $2 \mathrm{FI}$ & 13.52 & 6 & 2.25 & 32.49 & 0.0024 & \\
\hline Quadratic & 0.85 & 3 & 0.28 & 4.09 & 0.1035 & Suggested \\
\hline$\overline{\text { Cubic }}$ & 0.000 & 0 & - & - & - & Aliased \\
\hline
\end{tabular}

Model summary statistics

\begin{tabular}{llllll}
\hline Source & Std. dev. & $R^{2}$ & Adjusted $R^{2}$ & Predicted $R^{2}$ & Press \\
\hline Linear & 1.14 & 0.8205 & 0.7791 & 0.6297 & 35.04 \\
2FI & 1.17 & 0.8542 & 0.7667 & 0.2730 & 68.78 \\
Quadratic & 0.40 & 0.9881 & 0.9727 & 0.8515 & 14.05 \\
Cubic & 0.26 & 0.9971 & 0.9883 & - & Suggested
\end{tabular}

${ }^{a}$ Underline values show the higher significance. 
results of these evaluations have been exhibited in Table 2 . The quadratic model was found to be the most suitable model for the optimization of polymerization reaction among four studied types of BBD because of maximum $R^{2}$, adjusted $R^{2}$, predicted $R^{2}$ and the low standard deviation. Thereafter, the analysis of variance (ANOVA) further justified the adequacy of the model (Table 2). As shown in Table 2, all of the linear, interactive (two factor interactions $=2 \mathrm{FI}$ ), quadratic and cubic models were fitted to the experimental data.

3.3.2. Fitting of second order polynomial equation. Based on the BBD model and the input variables, a transformed model (PY') was recommended by the Box-Cox transformation technique after performing the initial ANOVA and investigating the adequacy of the original PY data. Since the original PY data was not normally distributed and the initial approximation of the mathematical relationship of the original PY data on the independent variables had a significant lack of fit, the Box-Cox power transformation was applied on the data. ${ }^{33}$ The Box-Cox power transformation was performed by adding a constant value $(k)$ equal to 0.784 to the original PY followed by calculating the square root of the data as shown in eqn (5). This second-order polynomial equation explained the relationship of the three variables in terms of coded factors with all terms regardless of their significance. Quadratic relationships and interaction terms are illustrated by the coefficients with higher order terms and more than one factor term, respectively. The positive sign indicates a synergistic effect whereas a negative sign indicates an antagonistic effect. ${ }^{34}$

$$
\begin{aligned}
\mathrm{PY}^{\prime}= & \sqrt{\mathrm{PY}+0.78} \\
= & 3.77+1.02 X_{1}+2.90 X_{2}+0.60 X_{3}-1.04 X_{1}{ }^{2}+1.25 X_{2}{ }^{2} \\
& -0.70 X_{3}{ }^{2}+0.71 X_{1} X_{2}+0.31 X_{1} X_{3}+0.41 X_{2} X_{3}
\end{aligned}
$$

3.3.3. Statistical analysis. The ANOVA was employed to analyze the experimental data and evaluate the significance of the regression coefficients by their corresponding $p$-values presented in Table 3.

$P$-Values less than 0.0500 indicate model terms are significant or not. ${ }^{35}$ So, it could be inferred that the linear coefficients $\left(X_{1}, X_{2}\right.$, and $\left.X_{3}\right)$, quadratic coefficients $\left(X_{1}^{2}, X_{2}{ }^{2}\right.$ and $\left.X_{3}^{2}\right)$ and interactive coefficients $\left(X_{1} X_{2}, X_{1} X_{3}\right.$, and $\left.X_{2} X_{3}\right)$ were significant or insignificant and prove the pattern of the interactions between the variables. ${ }^{35}$ The $p$-values of model terms indicate that the linear and quadratic as well as one of the interactive coefficients $\left(X_{1} X_{2}\right)$, were significant. As shown in Table 3 , the Model $F$-value of 67.01 suggested the model is significant at $p<0.0001$. The lack of fit $F$-value of 4.09 and the associated $p$-value of 0.1035 was insignificant. The determination coefficient $\left(R^{2}\right)$, adjusted determination coefficient $\left(R_{\alpha}{ }^{2}\right)$, and predicted determination coefficient $\left(R_{\mathrm{p}}{ }^{2}\right)$ were also evaluated to confirm that the model fits properly as listed in Table 4 . The $R^{2}$ equal to 0.9885 of the quadratic regression model indicated that the model has a good fit and only $0.0115 \%$ of the total variations could not be explained by the model. Joglekar and May (1987) suggested $R^{2}$ should be more than 0.80 for a good fit of a model. ${ }^{36}$ The adjusted determination coefficient $\left(R_{\alpha}{ }^{2}\right)$ equal to 0.9738 further confirmed the significance of the model. Moreover, the $R^{2}$ and

\begin{tabular}{|c|c|c|c|c|c|c|c|c|}
\hline Source & $\begin{array}{l}\text { Coefficient } \\
\text { estimate }\end{array}$ & Sum of squares & Degree of freedom & Standard error & Mean square & $F$ value & $p$-Value & \\
\hline Model & 3.77 & 93.49 & 9 & 0.18 & 10.39 & 64.42 & $<0.0001$ & Significant \\
\hline$X_{1}$ & 1.01 & 8.16 & 1 & 0.14 & 8.16 & 50.60 & 0.0002 & \\
\hline$X_{2}$ & 2.88 & 66.57 & 1 & 0.14 & 66.57 & 412.88 & $<0.0001$ & \\
\hline$X_{3}$ & 0.60 & 2.90 & 1 & 0.14 & 2.90 & 17.99 & 0.0038 & \\
\hline$X_{1}^{2}$ & -1.02 & 4.42 & 1 & 0.20 & 4.42 & 27.43 & 0.0012 & \\
\hline$X_{2}^{2}$ & 1.26 & 6.72 & 1 & 0.20 & 6.72 & 41.69 & 0.0003 & \\
\hline$X_{3}^{2}$ & -0.71 & 2.14 & 1 & 0.20 & 2.14 & 13.25 & 0.0083 & \\
\hline$X_{1} X_{2}$ & 0.73 & 2.14 & 1 & 0.20 & 2.14 & 13.29 & 0.0082 & \\
\hline$X_{1} X_{3}$ & 0.31 & 0.38 & 1 & 0.20 & 0.38 & 2.39 & 0.1662 & \\
\hline$X_{2} X_{3}$ & 0.41 & 0.66 & 1 & 0.20 & 0.66 & 4.07 & 0.0835 & \\
\hline Residual & & 1.13 & 7 & & 0.16 & & & \\
\hline Lack of fit & & 0.85 & 3 & & 0.28 & 4.09 & 0.1035 & Not sig. \\
\hline Pure error & & 0.28 & 4 & & 0.069 & & & \\
\hline Cor total & & 94.62 & 16 & & & & & \\
\hline
\end{tabular}

Table 3 ANOVA of the regression model for the prediction of yield\% of ring-opening polymerization of 1,2-epoxydecane through microwave method

Table 4 Summary of the regression analysis response of area ratio for fitting to the quadratic model

\begin{tabular}{llllll}
\hline$R^{2}$ & Adjusted $R^{2}$ & Predicted $R^{2}$ & Mean $\pm \mathrm{SD}$ & CV, \% & Adequate precision \\
\hline 0.9881 & 0.9727 & 0.8515 & $3.55 \pm 0.40$ & 11.33
\end{tabular}


$R_{\alpha}{ }^{2}$ values are close enough to indicate a high correlation between the experimental and the predicted values. ${ }^{28}$ In addition, the predicted determination coefficient $\left(R_{\mathrm{p}}{ }^{2}\right)$ equal to
0.8585 was in a reasonable agreement with the adjusted determination coefficient $\left(R_{\alpha}{ }^{2}\right)$ (Table 4). Finally, the signal to noise ratio greater than 4 provides the adequate precision measure. ${ }^{37}$

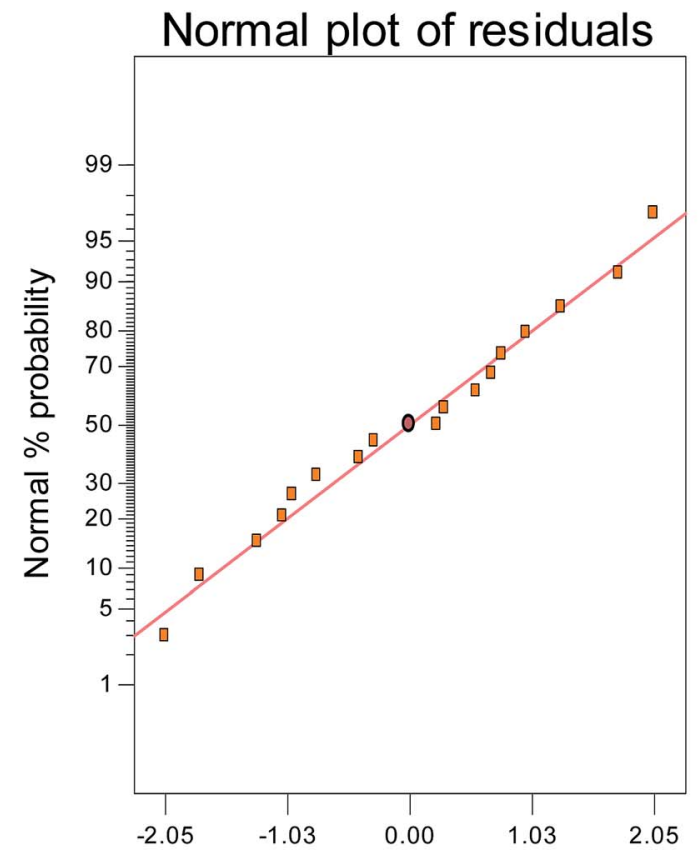

Studentized Residuals

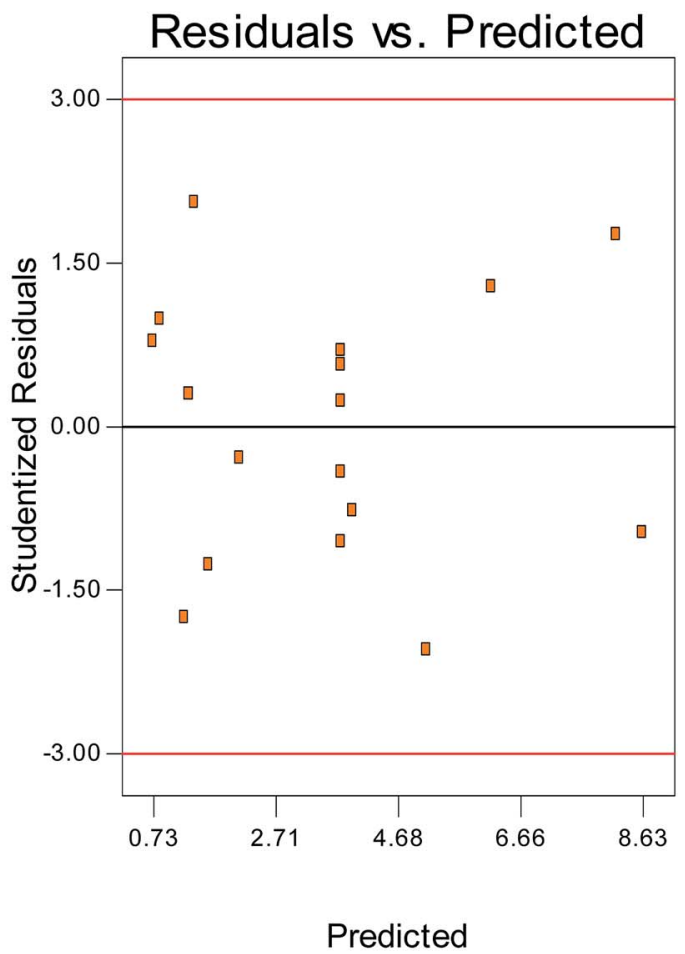

b)

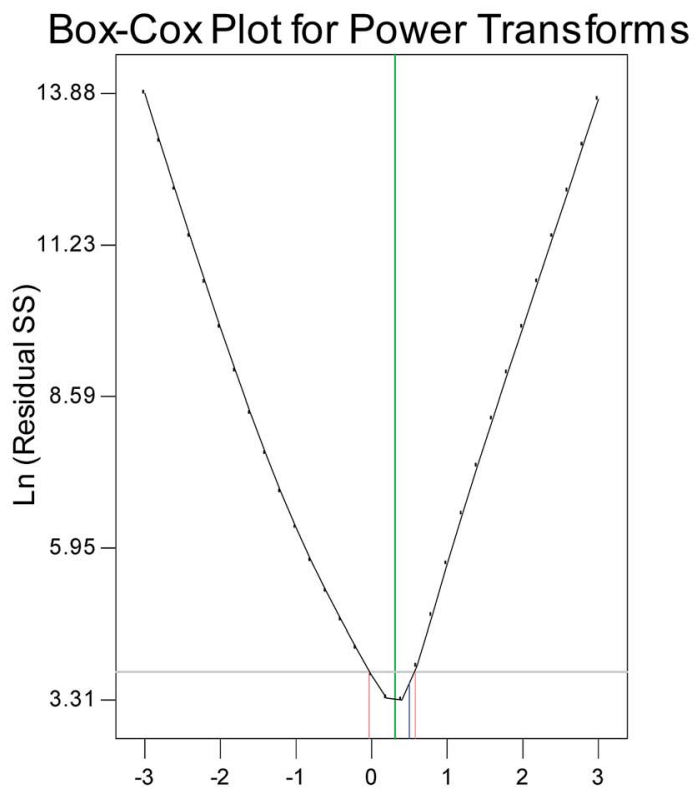

Lambda

c)

Run Number

d)

Fig. 2 Diagnostic plots for the model adequacy. 
As this ratio was 26.056, the model indicated an adequate signal, too. Therefore, the model was authenticated based on the aforementioned result that can be used to navigate the design space.

3.3.4. Diagnostics of model adequacy. Model adequacy was checked to diagnose if the approximating model would provide poor or misleading results. The normal probability\% plot of the studentized residuals, studentized residuals versus predicted values, the influence plots outlier $t$ versus run order and BoxCox plot were the diagnostic plots to be checked for the model adequacy (Fig. 2). Fig. 2a plotted the normal\% probability versus the studentized residuals for the response. The resulting plot is linear indicating the normality of residuals. Fig. $2 \mathrm{~b}$ shows a reasonable random scattering of the predicted values versus studentized residuals which are necessary for an adequate model. The influence plots outlier $t$ versus experimental run orders was also checked for influential values (Fig. 2c). There were no data out of the limit lines to force a lack of fit on the model with a heavy influence on the data. Finally, Box-Cox plot was used to determine whether the power law transformation would be appropriate for the model or not. Fig. $2 \mathrm{~d}$ shows that the best results for normality were reached with Lambda values between -0.03 and 0.58 after power transformation. Although the best value is 0.31 , the chosen Lambda is 0.5 (the closest whole number to 0.31 ) which indicates a $95 \%$ confidence interval associated with this lambda value. Therefore, the transformation was employed correctly and the diagnostic plots illustrated the accuracy of the developed model.

3.3.5. Effect of process variables on the PY. The threedimensional (3D) response surface graphs, obtained from the developed model, were used to clarify the main and interactive effects of independent variables on the PY. These 3D graphs were drawn by keeping one factor constant (in turn at its coded zero value), and investigating the other two factors in their range. Fig. 3 shows that all the relationship between independent variables was non-linear in accordance with the eqn (5). Fig. 3a shows that although the interactive effect of the temperature and irradiation time increased the PY, the temperature has the greater effect on PY. The interactive effect of the irradiation time and the solvent-monomer ratio has been illustrated in Fig. 3b. They both have a positive effect on the PY. However, the irradiation time is more effective than the solventmonomer ratio on PY. Fig. 3c which demonstrates the interactive effect of solvent-monomer ratio and the temperature on the PY indicates a more pronounced effect of temperature on the PY compared to the solvent-monomer ratio. Since toluene (dielectric constant $=2.38$ and boiling point $=110^{\circ} \mathrm{C}$ ) is a nonpolar solvent and almost transparent to the MW irradiation, ${ }^{19}$ it only affects the PY by providing a less viscous reaction media. The temperature, however, affects the monomer-catalyst interaction to provide the highest PY. This might be due to the significant effect of temperature on the catalytic activity of the MMAO-12/2,4-pentanedione in ROP of the terminal epoxide. ${ }^{11}$

3.3.6. Optimization and verification of the model. The optimum process conditions for the maximum PY were predicted using a desirability ramp in the software. The optimum conditions with a desirability value of 1 predicting $82.51 \%$ of

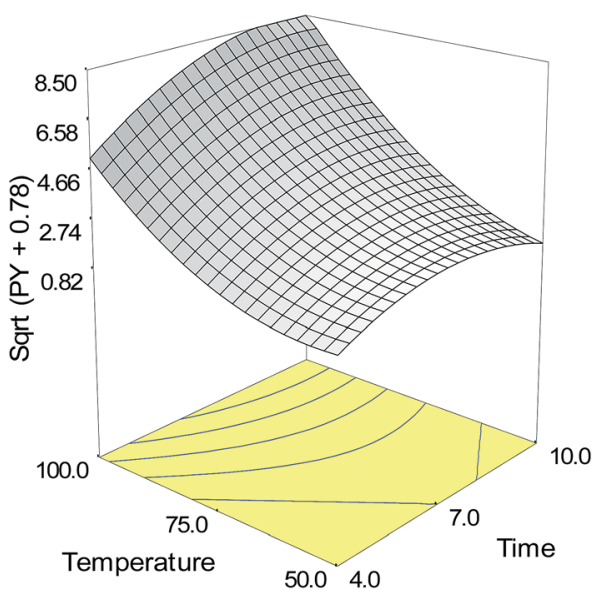

a)

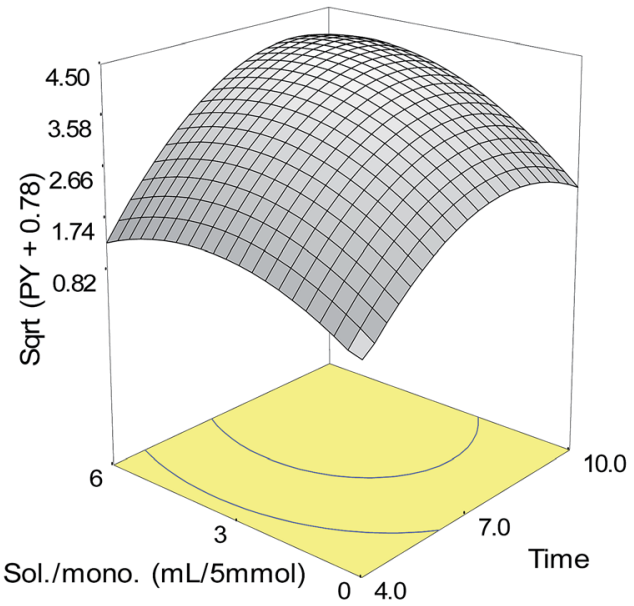

b)

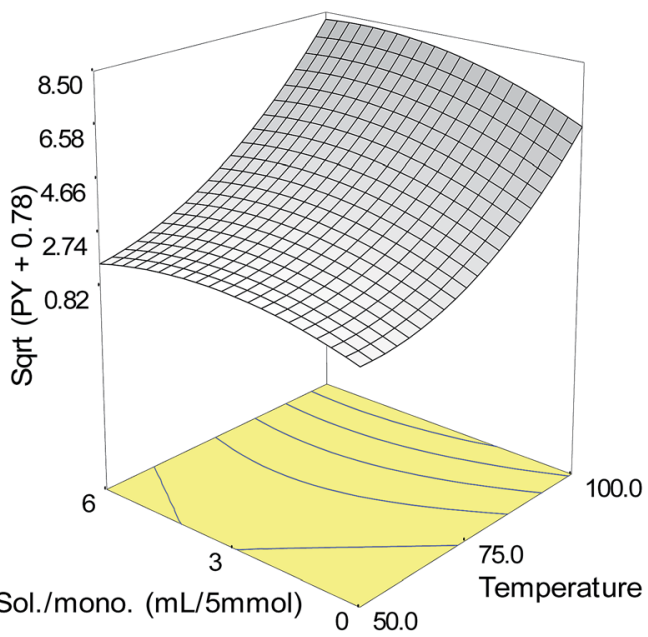

c)

Fig. 3 Response surface plots showing the effect of independent variables for yield\% of ring-opening polymerization of 1,2-epoxydecane through microwave method. 
polymerization yield were $t=9.97 \mathrm{~min}, T=99.69{ }^{\circ} \mathrm{C}$, and $5.27: 5$ for the solvent-monomer ratio. Triplet confirmatory experiments were conducted for the validation of the model. The optimum conditions along with 2 more conditions with different solvent-monomer ratios (Table 5) for maximum predicted yield were used to confirm the model and investigate the effects of solvent volume on the molecular weight of the polyether. Table 5 summarizes the confirmatory conditions, the predicted and observed PY as well as the molecular weights of the obtained polymers. The observed PY has a good agreement with the predicted PY in all of the selected runs. This indicates the efficiency of the Box-Behnken design incorporated with desirability function in optimizing conditions for the PY in the microwave assisted ring-opening polymerization of 1,2epoxydecane.

\subsection{Molecular weight of the polyether}

The polymer was heated at $50{ }^{\circ} \mathrm{C}$ in THF for $5 \mathrm{~min}$ to be used in GPC. As shown in Table 5, the molecular weight of all polyethers was above one million $\left(\mathrm{g} \mathrm{mol}^{-1}\right)$. Surprisingly, the molecular weight of the polyether produced with optimum conditions of the MW in less than $10 \mathrm{~min}$ was $2.12 \times 10^{6}\left(\mathrm{~g} \mathrm{~mol}^{-1}\right)$ which was comparable to that of produced by the conventional method after 24 hours $\left(2.40 \times 10^{6} \mathrm{~g} \mathrm{~mol}^{-1}\right)$ and reported in the literature. ${ }^{11}$ Warwel et al. referred the remarkably slow polymerization of $\omega$-epoxied olefins in the conventional method to the improper catalyst monomer interaction. Although they tried to solve the problem using temperatures above $100{ }^{\circ} \mathrm{C}$ with the help of higher boiling solvents such as $m$-xylene, and 1,2,4-trichloro benzene (TCB), they were not successful and saw a drastic decrease in the molecular weight of polymers. ${ }^{11}$ Therefore, our study proved that the ROP of $\omega$-epoxied olefins with MMAO-12/2,4-pentanedione can be accelerated using MW irradiation through the improvement of the catalyst-monomer interactions.

3 different levels of solvent-monomer ratios were also investigated in the MW method. The solvent-monomer ratio has a direct effect on the molecular weight and yield of the polyether. Although the MW assisted bulk polymerization of 1,2-epoxydecane resulted in polyether of molecular weight $1.16 \times 10^{6}\left(\mathrm{~g} \mathrm{~mol}^{-1}\right)$ but by increasing solvent-monomer ratio from $0: 5$ to $5.25: 5$ enhanced the molecular weight of the polyether to $2.12 \times 10^{6}\left(\mathrm{~g} \mathrm{~mol}^{-1}\right)$. Similar to the conventional method, the polydispersity of the polyether synthesized using optimum microwave conditions was considerably narrow $(D=1.15)$ (Table 5$)$. The narrow polydispersity of the polyethers produced using a higher ratio of the solvent both in MW and conventional method was

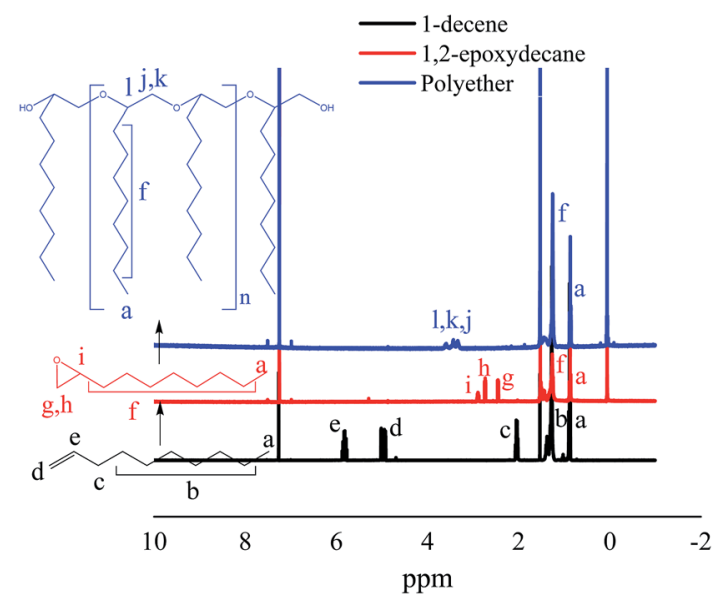

Fig. $4400 \mathrm{MHz}{ }^{1} \mathrm{H}-\mathrm{NMR}\left(\mathrm{CDCl}_{3}\right)$ spectra of two steps conversion of 1-decene to 1,2-epoxydecane and then polyether.

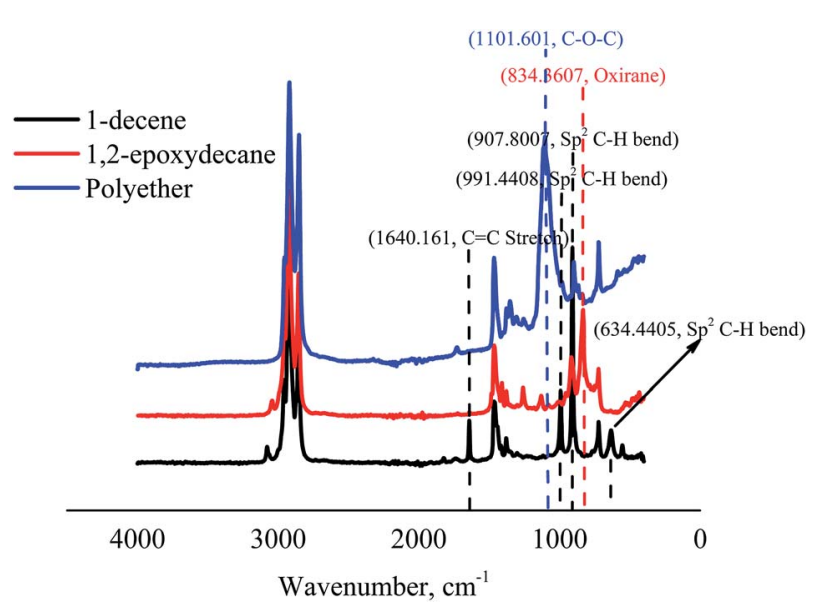

Fig. 5 ATR-FTIR analysis of two steps conversion of 1-decene to 1,2epoxydecane and then polyether.

Table 5 A comparison between the yield\% and GPC results of the optimum microwave method, two selected conditions with the different amount of the solvent-monomer ratio resulted in highest predicted yield $\%$ and the conventional method

\begin{tabular}{|c|c|c|c|c|c|c|c|c|c|}
\hline Run & Time (min) & Temp. $\left({ }^{\circ} \mathrm{C}\right)$ & $\begin{array}{l}\text { Solvent : monomer } \\
\text { ratio }(\mathrm{mL}: \mathrm{mmol})\end{array}$ & Desirability & $\begin{array}{l}\text { Predicted } \\
\text { PY }(\%)\end{array}$ & $\begin{array}{l}\text { Observed }^{c} \\
\text { PY }(\%)\end{array}$ & $\begin{array}{l}M_{\mathrm{n}} \times 10^{6} \\
\left(\mathrm{~g} \mathrm{~mol}^{-1}\right)\end{array}$ & $\begin{array}{l}M_{\mathrm{w}} \times 10^{6} \\
\left(\mathrm{~g} \mathrm{~mol}^{-1}\right)\end{array}$ & $M_{\mathrm{w}} / M_{\mathrm{n}}$ \\
\hline 1 & 9.97 & $99.69^{a}$ & $5.27: 5$ & 1 & 82.51 & $80 \pm 1.6$ & 1.8476 & 2.1247 & 1.15 \\
\hline 3 & 9.05 & 100 & $0: 5$ & 0.75 & 44.08 & $47 \pm 3.02$ & 0.25988 & 1.1617 & 4.4703 \\
\hline $4^{b}$ & $24 \mathrm{~h}$ & 100 & $6: 5$ & - & - & - & 1.9807 & 2.4019 & 1.2 \\
\hline
\end{tabular}

${ }^{a}$ The software of the microwave was just able to adjust whole numbers of temperature, so $100{ }^{\circ} \mathrm{C}$ was used in this runs. Meanwhile, the maximum variance in the adjusted temperature on the machine is less than $\pm 2{ }^{\circ} \mathrm{C}$ during hold time. ${ }^{b}$ Conventional method. ${ }^{c}$ Average of the three experiments. 
probably due to the solubility of the polyethers in the solvent. However, when the solvent ratios were decreased, the polydispersity of the polyethers became considerably broad. It is possibly due to the difference in the initiation time of different changes resulting from an uncontrolled polymerization process and the decrease of the propagation rate due to increase in viscosity with time which leads to new chains with low molecular mass and high polydispersity.

\subsection{Confirmation of epoxidation and polymerization reactions}

The structure of the epoxidized monomer and the produced polyether was analyzed by ${ }^{1} \mathrm{H}$-NMR and ATR-FTIR. A typical ${ }^{1} \mathrm{H}$ NMR spectrum of the synthesized polyether from 1-decene is presented in Fig. 4. The spectrum clearly supports the epoxidation of 1-decene and the formation of polyether from 1,2epoxydecane. Comparison of ${ }^{1} \mathrm{H}-\mathrm{NMR}$ spectra of 1-decene and its epoxidized form demonstrated successful oxidation through the disappearance of the terminal double bond peaks at 2.04-

\section{a) Initiation}

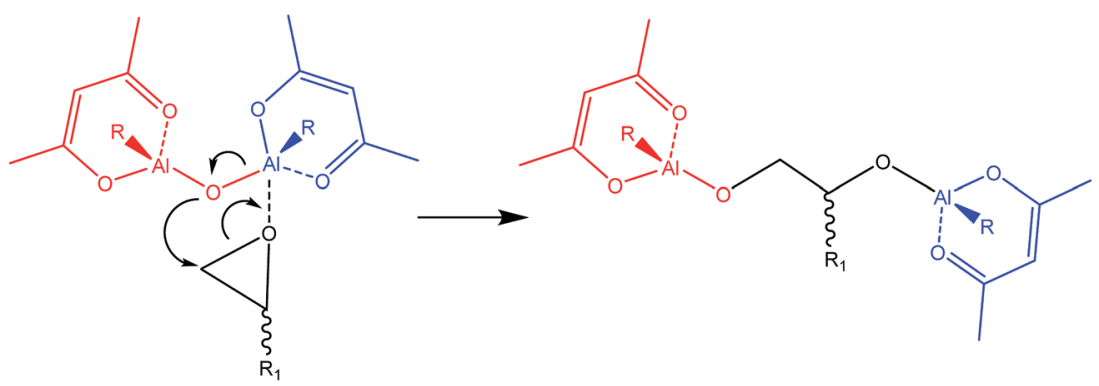

\section{b) Propagation}

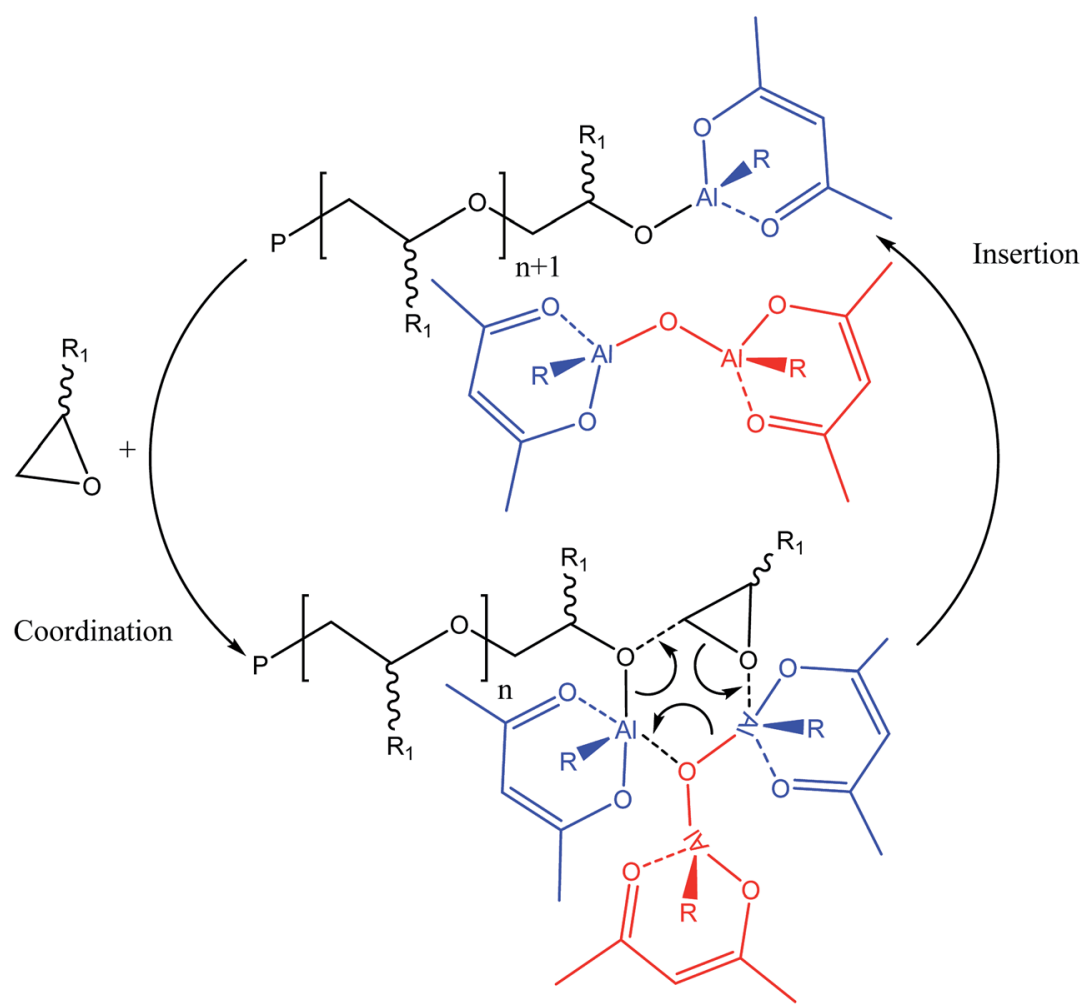

Fig. 6 The mechanism of the coordinative ring-opening polymerization. 
$5.82 \mathrm{ppm}$ and appearance of the epoxy group peaks at 2.462.9 ppm. ${ }^{32,38}$ The shift of epoxy group peaks to the $\partial 3.38-$ $3.58 \mathrm{ppm}$ region confirms the generation of the ether linkage after ROP.

Further confirmation of the whole process was done by the changes in the ATR-FTIR spectrum signals (Fig. 5). FTIR spectra of 1-decene and 1,2-epoxydecane revealed the disappearance of $\mathrm{C}=\mathrm{C}$ peaks $\left(\sim 1640 \mathrm{C}=\mathrm{C}\right.$ stretch$, \sim 991, \sim 907$, and $\sim 634 \mathrm{~cm}^{-1}$ of $\mathrm{sp}^{2} \mathrm{CH}$ bend of alkene) and the appearance of oxirane ring peak at $\sim 834 \mathrm{~cm}^{-1}$. Two small peaks in the region between $\sim 1130$ and $1260 \mathrm{~cm}^{-1}$ might be related to the acyl and alkoxy groups of ethyl acetate solvent used in column chromatography during purification. Additionally, the oxirane peak was disappeared in the polyether spectrum and a clear peak related to ether linkages appeared at $\sim 1101 \mathrm{~cm}^{-1}$.

According to the catalyst nature, a coordinative ringopening polymerization mechanism can be expected for the 1,2-epoxydecane which is described in the literature. The initiation proceeds by the nucleophilic attack of the oxygen in the catalyst $\mathrm{Al}-\mathrm{O}-\mathrm{Al}$ system over the oxirane ring coordinated to a neighboring metal center. Therefore, the oxirane of the monomer opens and the monomer is inserted between the coordinated $\mathrm{Al}$ and the rest of the $\mathrm{Al}-\mathrm{O}-\mathrm{Al}$ bond system (Fig. 6a). The propagation step happens as a coordination insertion process. The oxygen on the monomer oxirane ring is coordinated by an $\mathrm{Al}$ on the catalyst active site. Then, ringopening occurs subsequently by the nucleophilic attack of the oxygen at the end of the growing chain and inserting the epoxide between that oxygen and the coordinated Al while the released $\mathrm{Al}$ from the end of the growing chain and participating catalyst in reaction regenerates the bimetallic catalyst again (Fig. 6b). Ideally, the growing chain moves alternatively between two vicinal $\mathrm{Al}$ atoms in a "flip-flop" way and leads to linear polyethers with $\mathrm{Al}-\mathrm{O}-\mathrm{C}$ bonds at both ends, and their acidic hydrolysis through the precipitation step will produce a polyetherdiol. ${ }^{11,39}$

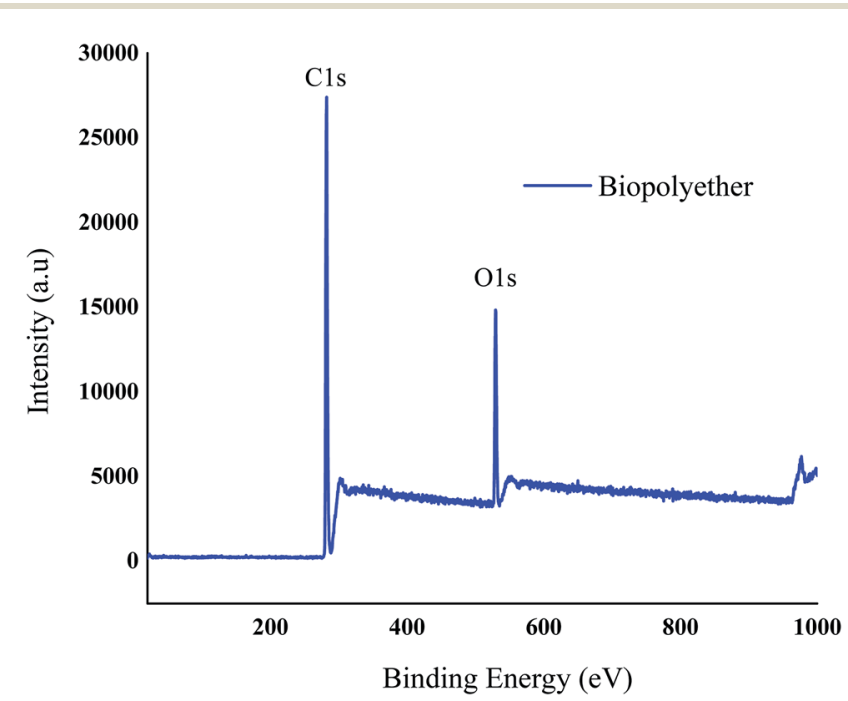

Fig. 7 X-ray Photoelectron Spectroscopy (XPS) survey spectra of the polyether.

\subsection{X-ray photoelectron spectroscopy (XPS)}

XPS was used to observe the elemental composition and functional groups of the polyether. The peaks observed in the spectrum at about 529, 282, and $101 \mathrm{eV}$ are due to $\mathrm{O} 1 \mathrm{~s}$ and $\mathrm{C} 1 \mathrm{~s}$ respectively. ${ }^{40}$ Fig. 7 clearly shows that the polyether is composed of carbon and oxygen only. The elemental composition of the polyether was $78.23 \%$ and $12.77 \%$ for the carbon and oxygen, respectively.

\subsection{Thermal properties of the polyether}

The thermal properties of the polyethers produced using the optimum conditions under MW irradiation and conventional method was studied using DSC and TGA. Typical DSC and TGA thermograms of the polyethers are shown in Fig. 8 and 9, respectively. DSC revealed a multiple melting endotherms for the polyethers with a complete melting observed at 34.1188.38 ${ }^{\circ} \mathrm{C}$ and $39.57-84.85^{\circ} \mathrm{C}$ in the microwave and conventional method, respectively. This phenomenon has been referred to the complex structure of the polyether with the tactic and atactic regions. ${ }^{11}$

The polyethers exhibited a low glass transition temperature of $5.41{ }^{\circ} \mathrm{C}$ and $-5.62{ }^{\circ} \mathrm{C}$ in the conventional and microwave method, respectively. Generally, the presence of long dangling chains in the structure of the polyether provides a stronger plasticizing effect and gives a low glass transition temperature. ${ }^{\mathbf{4 1}}$ In addition, the shift of the glass transition temperature and the melting point in the polyether obtained from MW method could be due to the slight differences in the molecular weight and different proportions of isotactic and atactic polymer chains in MW and conventional methods. The glass transition temperature of atactic polypropylene has been reported lower than that of isotactic, ${ }^{42}$ therefore it is most probable that microwaves promote atacticity compared to conventional heating. The TGA curves illustrated a small weight loss in the range of $143-193{ }^{\circ} \mathrm{C}$

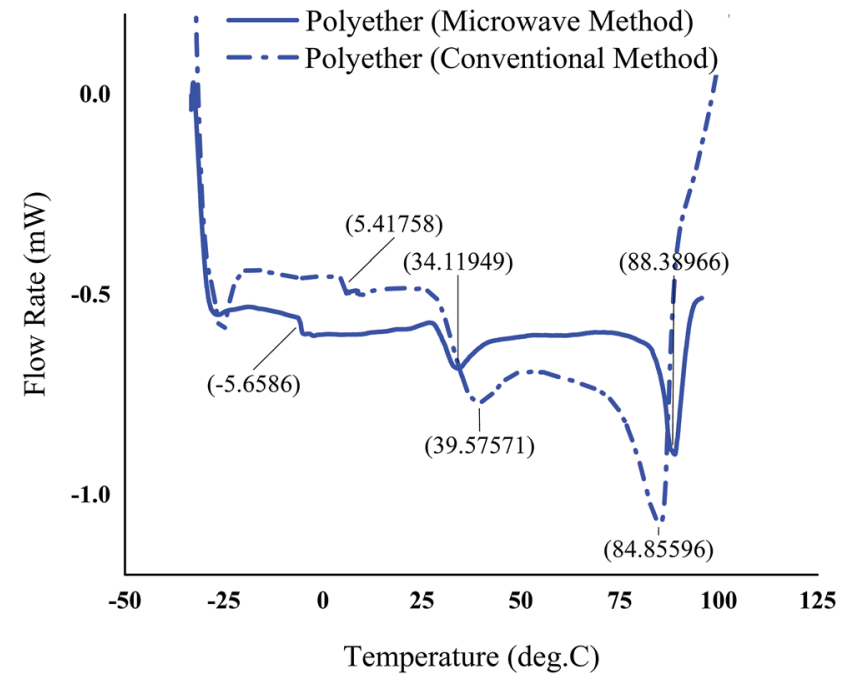

Fig. 8 DSC-thermogram of the polyether produced in the optimum process condition using the microwave as the heating source and conventional method. 


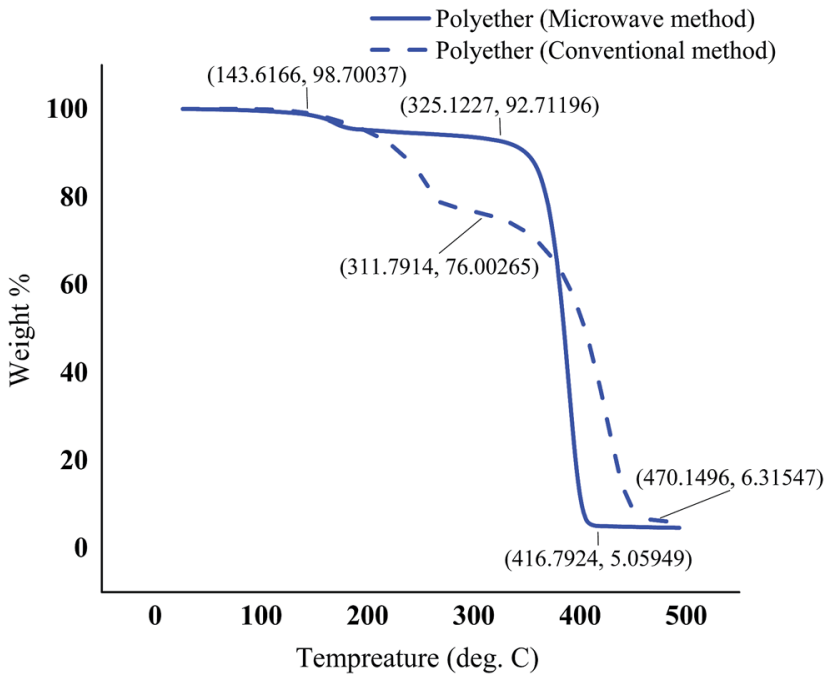

Fig. 9 TGA - thermogram of the polyethers produced using the optimum conditions under microwave irradiation and the conventional method.

possibly due to the presence of tiny amounts of the lower molecular weight polymers in both polyethers synthesized by conventional heating and microwaves. However, the major decomposition in the range of $325-418{ }^{\circ} \mathrm{C}$ was observed for the polyether resulted from microwave method. Nevertheless, a contrast to one major weight loss in microwave assisted synthesized polyether, the TGA of the polyether from the conventional method showed two major weight loss zones. First major weight loss at $\sim 200-400{ }^{\circ} \mathrm{C}$ and second between $400{ }^{\circ} \mathrm{C}$ and $500{ }^{\circ} \mathrm{C}$. It has also been reported that atactic polypropylene had higher thermal stability. ${ }^{43}$ Therefore, the second weight loss in polyether prepared by conventional heating at $\sim 200-400{ }^{\circ} \mathrm{C}$ could be attributed to a higher proportion of isotactic polyether and final weight loss between $400{ }^{\circ} \mathrm{C}$ and $500{ }^{\circ} \mathrm{C}$ is probably due to atactic polyether component.

\section{Conclusion}

This manuscript details with the production of a high molecular weight polyether from 1-decane, one of the main biorefinery products of the plant oils, through both conventional and the MW methods. The epoxidation reaction of 1-decene was optimized and successfully completed within 1 hour, a considerably short time without using catalyst, under conventional method. MW was not found suitable for performing the epoxidation reaction of 1-decane due to epoxy ring-opening by MW irradiation. Synthesized 1,2-epoxydecane was then used as the starting material for the production of a high molecular weight polyether. The polymerization yield was optimized using a three-factor, three-level Box-Behnken design for the MW method. The BBD appeared to be a suitable method for optimization of the reaction conditions to maximize the yield of the ring-opening polymerization of 1,2-epoxydecane. The optimum point was identified with the graphical response surface plots. The optimum conditions for the highest polyether yield were as follow $t=9: 97 \mathrm{~min}, T=99.69{ }^{\circ} \mathrm{C}$, and $5.27: 5$ solventmonomer ratio with a desirability value of 1 . The polyether produced with the optimum conditions of MW illustrated the highest yield and molecular weight in a good agreement with the results of the conventional method. This result confirmed that the MMAO-12/2,4-pentanedione have a good potential to use for ring- opening polymerization of the terminal olefins in the microwave method. Thermal properties study of the polyether showed a complete melting at $34.13-88.64{ }^{\circ} \mathrm{C}$ with the $T_{g}$ point of $-5.62{ }^{\circ} \mathrm{C}$ and the onset decomposition temperature of $325^{\circ} \mathrm{C}$.

\section{References}

1 S. Warwel, F. Bruse, C. Demes, M. Kunz and M. R. G. Klaas, Polymers and surfactants on the basis of renewable, Chemosphere, 2001, 43, 39-48.

2 K. Zhang, A. M. Nelson, S. J. Talley, M. Chen, E. Margaretta, A. G. Hudson, R. B. Moore and T. E. Long, Non-isocyanate poly(amide-hydroxy urethane)s from sustainable resources, Green Chem., 2016, 18, 4667-4681.

3 F. Pardal, S. Salhi, B. Rousseau, M. Tessier, S. Claude and A. Fradet, unsaturated polyamides from bio-based $\mathrm{z}$ octadec-9-enedioic acid, Macromol. Chem. Phys., 2008, 209, 64-74.

4 M. A. R. Meier, J. O. Metzger and U. S. Schubert, Plant oil renewable resources as green alternatives in polymer science, Chem. Soc. Rev., 2007, 36, 1788-1802.

5 L. Montero de Espinosa and M. A. R. Meier, Plant oils: The perfect renewable resource for polymer science?!, Eur. Polym. J., 2011, 47, 837-852.

6 T. S. Omonov and J. M. Curtis, Biobased epoxy resin from canola oil, J. Appl. Polym. Sci., 2014, 131, 40142.

7 G. Karmakar and P. Ghosh, Atom transfer radical polymerization of soybean oil and its evaluation as a biodegradable multifunctional additive in the formulation of eco-friendly lubricant, ACS Sustainable Chem. Eng., 2016, 4, 775-781.

8 K. R. Kunduru, A. Basu, M. H. Zada and A. J. Domb, Castor oil-based biodegradable polyesters, Biomacromolecules, 2015, 16, 2572-2587.

9 P. J. Roumanet, F. Laflèche, N. Jarroux, Y. Raoul, S. Claude and P. Guégan, Novel aliphatic polyesters from an oleic acid based monomer. Synthesis, epoxidation, cross-linking and biodegradation, Eur. Polym. J., 2013, 49, 813-822.

10 O. Türünç, M. Firdaus, G. Klein and M. A. R. Meier, Fatty acid derived renewable polyamides via thiol-ene additions, Green Chem., 2012, 14, 2577.

11 S. Warwel, B. Wiege, E. Fehling and M. Kunz, Ring-opening polymerization of oleochemical epoxides catalyzed by aluminoxane/acetylacetone, Eur. Polym. J., 2000, 36, 26552663.

12 M. Arshad, S. Saied and A. Ullah, PEG-lipid telechelic incorporating fatty acids from canola oil: synthesis, characterization and solution self-assembly, RSC Adv., 2014, 4, 26439-26446. 
13 S. Chikkali and S. Mecking, Refining of plant oils to chemicals by olefin metathesis, Angew. Chem., Int. Ed., 2012, 51, 5802-5808.

14 Y. Takahira and Y. Morizawa, Ruthenium-catalyzed olefin cross-metathesis with tetrafluoroethylene and analogous fluoroolefins, J. Am. Chem. Soc., 2015, 137, 7031-7034.

15 A. H. Hoveyda and A. R. Zhugralin, The remarkable metalcatalysed olefin metathesis reaction, Nature, 2007, 450, 243-251.

16 A. Ullah and M. Arshad, Remarkably efficient microwaveassisted cross-metathesis of lipids in solvent-free conditions, ChemSusChem, 2017, 10, 2167-2174.

17 T. Sabu and P. M. Visakh, Handbook of Engineering and Speciality Thermoplastics, John Wiley \& Sons Inc., and Scrivener Publishing LLC., USA, 2011.

18 G. N. Gaylord, High polymers, John Wiley \& Sons, Inc., USA, 1962.

19 J. T. Pelle Lidström, B. Wathey and J. Westman, Microwave assisted organic synthesis-a review, Tetrahedron, 2001, 57, 9225-9283.

20 R. Hoogenboom and U. S. Schubert, Microwave-assisted polymer synthesis: recent developments in a rapidly expanding field of research, Macromol. Rapid Commun., 2007, 28, 368-386.

21 S. Sinnwell and H. Ritter, Recent advances in microwaveassisted polymer synthesis, Aust. J. Chem., 2007, 60, 729-743.

22 C. Zhang, L. Liao and L. Liu, Rapid ring-opening polymerization of D,L-lactide by microwaves, Macromol. Rapid Commun., 2004, 25, 1402-1405.

23 M. B. Gawande, S. N. Shelke, R. Zboril and R. S. Varma, Microwave-assisted chemistry: synthetic applications for rapid assembly of nanomaterials and organics, Acc. Chem. Res., 2014, 47, 1338-1348.

24 F. Wiesbrock, R. Hoogenboom, C. H. Abeln and U. S. Schubert, Single-mode microwave ovens as new reaction devices: accelerating the living polymerization of 2-ethyl-2-oxazoline, Macromol. Rapid Commun., 2004, 25, 1895-1899.

25 Y. Li, X. L. Wang, K. K. Yang and Y. Z. Wang, A rapid synthesis of poly(p-dioxanone) by ring-opening polymerization under microwave irradiation, Polym. Bull., 2006, 57, 873-880.

26 ASTM COMPASS, DOI: 10.1520/E1356, accessed 2016.

27 ASTM COMPASS, DOI: 10.1520/D3850-12, accessed 2016.

28 M. Kousha, E. Daneshvar, H. Dopeikar, D. Taghavi and A. Bhatnagar, Box-Behnken design optimization of Acid Black 1 dye biosorption by different brown macroalgae, Chem. Eng. J., 2012, 179, 158-168.

29 M. Iqbal, S. Faiyaz and A. Tarique, Simple and sensitive UPLC-MS/MS method for high-throughput analysis of ibrutinib in rat plasma: optimization by Box-Behnken experimental design, J. AOAC Int., 2016, 99, 618-625.

30 M. R. Klaas and S. Warwel, Lipase-catalyzed preparation of peroxy acids and their use for epoxidation, J. Mol. Catal. A: Chem., 1997, 117, 311-319.
31 K. P. Ho, W. L. Wong, K. M. Lam, C. P. Lai, T. H. Chan and K. Y. Wong, A simple and effective catalytic system for epoxidation of aliphatic terminal alkenes with manganese(II) as the catalyst, Chem.-Eur. J., 2008, 14, 7988-7996.

32 S. Kazuhiko, M. Aoki, M. Ogawa, T. Hashimoto and R. Noyori, A practical method for epoxidation of terminal olefins with $30 \%$ hydrogen peroxide under halide-free conditions, J. Org. Chem., 1996, 61, 8310-8311.

$33 \mathrm{~J}$. W. Osborne, Improving your data transformations: Applying the Box-Cox transformation, Practical Assessment, Research and Evaluation, 2010, 15, 1-9.

34 A. A. Karnachi and M. A. Khan, Box-Behnken design for the optimization of formulation variables of indomethacin coprecipitates with polymer mixtures, Int. J. Pharm., 1996, 131, 9-17.

35 S. N. Azizi and N. Asemi, A Box-Behnken design for determining the optimum experimental condition of the fungicide (Vapam) sorption onto soil modified with perlite, J. Environ. Sci. Health, Part B, 2012, 47, 692-699.

36 C. Tian, S. Fu, J. Chen, Q. Meng and L. A. Lucia, Graft polymerization of $\varepsilon$-caprolactone to cellulose nanocrystals and optimization of grafting conditions utilizing a response surface methodology, Nord. Pulp Pap. Res. J., 2014, 29, 58-68.

37 J. P. Maran, S. Manikandan, K. Thirugnanasambandham, C. V. Nivetha and R. Dinesh, Box-Behnken design based statistical modeling for ultrasound-assisted extraction of corn silk polysaccharide, Carbohydr. Polym., 2013, 92, 604611.

38 E. D. Rio, M. Galià, V. Càdiz, G. Lligadas and J. C. Ronda, Polymerization of Epoxidized Vegetable Oil Derivatives: Ionic-Coordinative Polymerization of Methylepoxyoleate, $J$. Polym. Sci., Part A: Polym. Chem., 2010, 48, 4995-5008.

39 Y. Imada, H. Iida, T. Kitagawa and T. Naota, Aerobic reduction of olefins by in situ generation of diimide with synthetic flavin catalysts, Chem.-Eur. J., 2011, 17, 5908-5920.

40 X. Gao, X. Hu, P. Guan, C. Du, S. Ding, X. Zhang, B. Li, X. Wei and R. Song, Synthesis of core-shell imprinting polymers with uniform thin imprinting layer via iniferter-induced radical polymerization for the selective recognition of thymopentin in aqueous solution, $R S C A d v$., 2016, 6, 110019-110031.

41 Z. S. Petrović, I. Cvetković, D. Hong, X. Wan, W. Zhang, T. W. Abraham and J. Malsam, Vegetable oil-based triols from hydroformylated fatty acids and polyurethane elastomers, Eur. J. Lipid Sci. Technol., 2010, 112, 97-102.

42 A. Gitsas and G. Floudas, Pressure Dependence of the Glass Transition in Atactic and Isotactic Polypropylene, Macromolecules, 2008, 41, 9423-9429.

43 H. Pasch, M. I. Malik and T. Macko, Recent Advances in High-Temperature Fractionation of Polyolefins, Adv. Polym. Sci., 2013, 251, 77-140. 